\title{
Erratum to: Informatics Curricula and Teaching Methods
}

\author{
Lillian Casse $^{1}$ and Ricardo A. Reis ${ }^{2}$ \\ 1 Villanova University, USA \\ 2 Universidade Federal do Rio Grande do Sul, Brazil
}

\section{Erratum to: \\ L. Cassel and R.A. Reis (Eds.) \\ Informatics Curricula and Teaching Methods DOI: $10.1007 / 978-0-387-35619-8$}

The book was inadvertently published with an incorrect name of the copyright holder. The name of the copyright holder for this book is: (c) IFIP International Federation for Information Processing. The book has been updated with the changes. 